\title{
Antibacterial Activities of Refined Deep Seawater on Helicobacter pylori
}

Masahiko Kawada ${ }^{1}$, Hiroaki Takeuchi² ${ }^{*}$, Sergio A. Con ${ }^{2,3}$, Etsuko Yamamoto ${ }^{1}$, Takeshi Yasukawa', Koji Nakagawa', Yoshinari lkegami ${ }^{1}$ and Tetsuro Sugiura ${ }^{2}$

Technical Development Division, Ako Kasei Co Ltd, Japan

2Department of Clinical Laboratory Medicine, Kochi Medical School, Nankoku, Kochi, Japan

${ }^{3}$ Centro Digestivo Doctores Con-Mediplaza, San Jose, Costa Rica

\begin{abstract}
Helicobacter pylori (H. pylori) is believed to infect about half of the world's population and is related to many gastric diseases, duodenal ulcer and a variety of non-gastrointestinal tract disorders. In this study, the inhibitory effects of refined deep seawater (RDSW) on $H$. pylori growth and motility were investigated. Deep seawater was collected offshore from Muroto, Kochi, Japan, desalinated, and refined to increase the mineral concentration. The in vitro assays with $16 \mathrm{H}$. pylori isolates by 20 types of RDSW with combinations of $5 \mathrm{Mg} / \mathrm{Ca}$ ratios and 4 degrees of hardness were performed. Bacterial growth and mobility were inhibited in a hardness-dependent manner. A difference in the $\mathrm{Mg} / \mathrm{Ca}$ ratio influenced the inhibitory effects when the degree of hardness was unchanged. At a hardness of 1000 , anti- $H$. pylori activities were observed in all strains for at least at one of the $5 \mathrm{Mg} / \mathrm{Ca}$ ratios. Evaluation of the anti- $\mathrm{H}$. pylori effects was then conducted in vivo in Mongolian gerbils, to which RDSW at 5 different $\mathrm{Mg} / \mathrm{Ca}$ ratios (hardness: 1000) was administered for 2 weeks. The number of $H$. pylori colonized in the stomach showed a significant decrease with 2 types of RDSW (C and D), compared with commercial mineral water. Furthermore, $1 \mathrm{~L}$ of each 5 types of RDSW was given daily for 10 days to healthy subjects infected with $H$. pylori. An urea breath test examined before and after the 10-day period showed reduction of $\Delta^{13} \mathrm{C}$ values in more of these subjects compared to controls who drank commercial mineral water. In vivo anti-H. pylori effects were observed in $\geq 90 \%$ of subjects drinking any of the 5 types of RDSW. These results raised the possibility that the application of refined deep seawater can be available for prevention of or as an adjuvant therapy for $H$. pylori infection.
\end{abstract}

Keywords: Helicobacter pylori; Refined deep seawater; Inhibitions of growth and motility; Anti-H. pylori activities in vivo; Urea breath test; Application for human health

\section{Introduction}

H. pylori persistently infects the gastric membrane and is a major cause of gastric diseases such as gastritis, gastric ulcer and duodenal ulcer $[1,2]$. A causal relationship of $H$. pylori with gastric cancer has been proposed [3] and recent studies have clarified the underlying mechanism [4]. In addition, $H$. pylori infection is associated with a variety of non-gastrointestinal tract disorders including autoimmune diseases such as immune thrombocytopenic purpura (ITP) [5]. H. pylori is currently believed to infect half of the world's population and there is a tendency for an increase in the infection rate, especially in developing countries. Among developed countries, Japan has a high infection rate of $H$. pylori and also has a higher percentage of occurrences of gastric cancer among all types of cancer.

Eradication of $H$. pylori can generally be achieved by the combined therapy consisting of two antibiotics and a proton pump inhibitor, but appearance of drug-resistant strains and side effects of the drugs are concerns in clinical practices. In Japan, the antibiotic used for H. pylori eradication is restricted (amoxicillin \& clarithromycin or amoxicillin \& metronidazole) due to health care services covered by health insurance. The side effects including headache, diarrhea, vertigo, nausea and so on appear in patients, resulting in failure of taking medicine. In addition to increased drug-resistant microorganism, instead of antibiotics, other compounds are of great concerned. Therefore, research on foods possessing the ability of anti- $H$. pylori activities is of interest, and the inhibitory effects on $H$. pylori have been described for green tea, honey, yoghurt, cranberry, aminoreductone, and other foods [6-9]. However, taking in foods or food-based components is necessary to pay attention to individual personal conditions such as taste, allergy and medical problems.
In Japan, deep seawater is collected at 16 facilities in Kochi, Toyama, and Okinawa Prefectures and refined deep seawater (RDSW) is widely used as drinking water. Beyond satisfying the general need for water to support life, RDSW has additional merits such as mineralrich, stability and clean. We previously performed clinical trial with 92 elderly volunteers in nursing care institution who are taking $3 \mathrm{~L} /$ day in their lifestyle for 10 months to assess the effect of RDSW on human body, demonstrating that taking RDSW significantly ameliorated their condition such as constipation, blood pressure, ratio of CD4/CD8 and so on. Furthermore, it should be noted that any types of RDSW have neither side effect even in a long-time heavy consumer nor demerit in a person with medical problems. These characteristics have led to the application of RDSW in the fishing industry, medical and engineering fields. RDSW can also alleviate atopic dermatitis, improve hyperlipidemia, and prevent arteriosclerosis as previously described, [10-12] and is therefore viewed as a healthy beverage. However, the functional effects of RDSW in the field of infectious disease have not been examined.

Thus, an investigation of the inhibitory effects of RDSW on the growth and motility of $H$. pylori was conducted in this study. RDSW

*Corresponding author: Hiroaki Takeuchi, Department of Clinical Laboratory Medicine, Kochi Medical School, Nankoku, Kochi 783-8505, Japan, Tel: +81-88880-2427; Fax: +81-88-880-2428; E-mail: htake@kochi-u.ac.jp

Received January 30, 2012; Accepted March 05, 2012; Published March 09 2012

Citation: Kawada M, Takeuchi H, Con SA, Yamamoto E, Yasukawa T, et al. (2012) Antibacterial Activities of Refined Deep Seawater on Helicobacter pylori. J Medical Microbiol Diagnosis S1:002. doi:10.4172/2161-0703.S1-002

Copyright: (C) 2012 Kawada M, et al. This is an open-access article distributed under the terms of the Creative Commons Attribution License, which permits unrestricted use, distribution, and reproduction in any medium, provided the original author and source are credited. 
conditioned to have different degrees of hardness and mineral ratios (magnesium and calcium) was used throughout this study. The initial objective of verifying the in vitro antibacterial effects of the RDSW against $H$. pylori was investigated. Next, these effects were examined in vivo in $H$. pylori-inoculated Mongolian gerbils and evaluated in asymptomatic subjects infected with $H$. pylori as a clinical trial.

\section{Materials and Methods}

\section{Conditioning of refined deep seawater (RDSW)}

RDSW was made using deep seawater collected at a depth of 344 $\mathrm{m}$ at a distance $2.2 \mathrm{~km}$ offshore from Muroto City in Kochi Prefecture. The deep seawater was desalinated and conditioned to give five magnesium:calcium (Mg:Ca) ratios of 1:2 (A), 1:1 (B), 3:1 (C), 1:0 (D) and 0:1 (E) at different concentrations to give levels of hardness of 100, 250, 500 and 1000. This approach produced 20 types of test water used in this study. The concentrations of magnesium and calcium in each type of RDSW are shown in Table 1.

\section{In vitro experiments}

Strains and culture conditions: Sixteen $H$. pylori strains including 2 sequenced reference strains (NCTC11637 and 26695), 9 clinical isolates, and 5 drug-resistant strains (clarithromycin and/or metronidazole) were used in the study. The 14 clinical isolates were obtained from patients with gastric cancer, gastric ulcer and normal gastric mucosa in Kochi Medical School Hospital. H. pylori was cultured in Brucella Broth (BB) agar medium (agar concentration of $1.4 \%$ ) (Nacalai Tesque) supplemented with $10 \%$ inactivated house serum (GIBCO) and $10 \mathrm{mg} / \mathrm{L}$ vancomycin hydrochloride (Eli Lilly Japan) at $37^{\circ} \mathrm{C}$ under $10 \% \mathrm{CO}_{2}$ condition as previously described [13] and was subsequently used for following bacterial growth and motility assays. Each agar test medium was made with 20 types of RDSW (100A to 1000-E) (Table 1). Soft agar medium (agar concentration: $0.25 \%$ ) was used in motility assay.

\section{Bacterial growth assay}

Each strain cultured on BB agar medium for 2 days was harvested with a platinum loop and suspended in BB liquid medium to condition the $\mathrm{OD}_{600}$ of 0.4 . These suspensions were diluted $1: 10^{4}, 1: 10^{5}$ and $1: 10^{6}$, and $10 \mu \mathrm{L}$ of the diluent was dropped into a control agar medium containing distilled water and each agar test medium. After these agar media were cultured for 3 days at $37^{\circ} \mathrm{C}$ under $10 \% \mathrm{CO}_{2}$ condition, the number of colonies grown was counted as expressed by colony forming unit (CFU)

\section{Bacterial motility assay}

Similarly, each strain well grown was scraped with a sterilized tooth pick and put in control soft agar medium containing distilled water and each soft agar test medium. These soft agar media were cultured for 7 days at $37^{\circ} \mathrm{C}$ under $10 \% \mathrm{CO}_{2}$ condition and then the diameter of each migrated colony was measured.

\section{Evaluation of inhibitory effects on $\mathrm{H}$. pylori}

The CFU and colony diameter in the control medium were set at $100 \%$ and an inhibitory effect was defined as a level of $80 \%$ of this value. Each assay was performed 3 times and a test water was judged to be active if an inhibitory effect was found in at least two of the three assays.

\section{In vivo experiments}

Control waters and test waters (RDSW) in animal experiments: Two types of control water (commercial mineral water of hardness about 30 and RDSW with no mineral content) and five test waters, (RDSW, all with hardness of 1000, but different mineral ratios: 1000-A to $1000-\mathrm{E}$ ) were used in the animal experiments (Table 1).

\section{Animal experiments}

Eight male Mongolian gerbils (MON/Jms/Gbs Slc, Japan SLC) aged 4 weeks in each group and $H$. pylori strain KYU1 possessing high

\begin{tabular}{|c|c|c|c|c|}
\hline Type of test water & Hardness $^{a}$ & Ratio of $\mathrm{Mg}: \mathrm{Ca}$ & Concentration of $\mathrm{Mg}(\mathrm{mg} / \mathrm{L})$ & Concentration of $\mathrm{Ca}(\mathrm{mg} / \mathrm{L})$ \\
\hline Control-1 (Mineral water) & 30 & $1: 6.4$ & 1.5 & 9.7 \\
\hline Control-2 (Deep seawater without minerals) & 0 & - & 0 & 0 \\
\hline $100-\mathrm{A}$ & 100 & $1: 2$ & 10 & 20 \\
\hline $100-B$ & & $1: 1$ & 15 & 15 \\
\hline $100-C$ & & $3: 1$ & 20 & 7 \\
\hline $100-\mathrm{D}$ & & Mg alone & 24 & 0 \\
\hline $100-E$ & & Ca alone & 0 & 35 \\
\hline $250-A$ & 250 & $1: 2$ & 25 & 50 \\
\hline $250-B$ & & $1: 1$ & 38 & 38 \\
\hline $250-C$ & & $3: 1$ & 50 & 18 \\
\hline $250-D$ & & Mg alone & 60 & 0 \\
\hline $250-E$ & & Ca alone & 0 & 88 \\
\hline $500-A$ & 500 & $1: 2$ & 50 & 100 \\
\hline $500-B$ & & $1: 1$ & 75 & 75 \\
\hline $500-C$ & & $3: 1$ & 100 & 35 \\
\hline $500-D$ & & Mg alone & 120 & 0 \\
\hline $500-E$ & & Ca alone & 0 & 175 \\
\hline $1000-A$ & 1000 & $1: 2$ & 100 & 200 \\
\hline $1000-B$ & & $1: 1$ & 150 & 150 \\
\hline $1000-C$ & & $3: 1$ & 200 & 70 \\
\hline 1000-D & & Mg alone & 240 & 0 \\
\hline 1000-E & & Ca alone & 0 & 350 \\
\hline
\end{tabular}

aHardness: $\mathrm{Ca}(\mathrm{mg} / \mathrm{L}) \times 2.5+\mathrm{Mg}(\mathrm{mg} / \mathrm{L}) \times 4.1$.

Table 1: Concentrations of $\mathrm{Mg}$ and $\mathrm{Ca}$ in test waters (RDSW). 
colonizing ability to Mongolian gerbil [14] were used in this study. The animals were allowed free access to solid food for mouse (CE-2, CLEA Japan) and control or test waters for two weeks. After this period, $0.5 \mathrm{~mL}$ of bacterial suspension by BB liquid medium $\left(\mathrm{OD}_{600}\right.$ of 0.4$)$ was orally administered for 2 consecutive days. Four weeks later, the animals were scarified under anesthesia with diethyl ether (cervical dislocation) and the stomach was removed. The stomach was weighed, homogenized by homogenizer, suspended in $1 \mathrm{~mL}$ of $\mathrm{BB}$ liquid medium and an aliquot of the suspension was applied to Helicobacter Agar Medium (Nissui). The agar medium was cultured in Anaero Pack (Mitsubishi Gas Chemical Company) for 5 days at $37^{\circ} \mathrm{C}$ and then the number of colonies grown (CFU) was counted. The CFU (henceforth referred to as the number of $H$. pylori colonized in the stomach) per $1 \mathrm{~g}$ of gastric tissue was determined and the value was evaluated in animals between drinking control and test waters. The mean \pm standard deviation of the CFU was compared among the groups by paired t-test, with $\mathrm{P}<0.05$ considered to be significant.

\section{Control waters and test waters (RDSW) in clinical trials}

Similarly, commercial mineral water mentioned above and 5 types of RDSW with a hardness of 1000, but different mineral ratios (1000-A to1000-E, Table 1) were used as a control and test waters in this study, respectively.

\section{Protocol for clinical trials}

The participants were 23 asymptomatic healthy Japanese adults infected with $H$. pylori, diagnosed by urea breath test $\left(\Delta^{13} \mathrm{C}>2.5 \%\right.$ ), who gave informed consent. We confirmed that all volunteers participated in this study that fulfilled the following criteria: absence of treatment with antibiotics or proton-pump inhibitors during the 4 weeks before the testing. The study was approved by the Ethics Committee of the institution. Control or test waters were given to subjects at $1 \mathrm{~L} /$ day for 10 days. A urea breath test was conducted before and after water intake. This test is usually used for diagnosis of $H$. pylori infection and evaluation of treatment outcome in clinical practice. The value of $\Delta^{13} \mathrm{C}$ is considered to semi-quantitatively reflect the number of $H$. pylori colonized in the stomach [15-17]. Thus, the change of value can be used to assess the effect of medicine on $H$. pylori colonization. The effect of RDSW on infection with $H$. pylori was evaluated by comparing $\Delta^{13} \mathrm{C}$ values before and after water intake. We pre-examined the fluctuation of UBT value to assess between-day precision with 5 volunteers for 1 week, indicating that the variation of UBT value keeps within an approximately $5 \%$. Based on this assumption, we adopted 7 $\%$ to strictly evaluate the effect of RDSW in this study. Thus, a decrease in $\Delta^{13} \mathrm{C}$ of $\geq 7 \%$ after water intake was defined as a successful outcome.

\section{Results}

\section{In vitro bacterial growth and motility assays}

The results of in vitro assays of bacterial growth and motility using 20 types of RDSW and 16 H. pylori strains are shown in (Table 2). As hardness increased, the proportion of strains that showed sensitivity to growth and motility inhibitions also increased. As for the growth inhibition, RDSW with hardness of 100 to 500 had little effect and there was little difference in the effects of different $\mathrm{Mg}$ :Ca ratios (types A-E). For hardness of 1000, the strongest inhibitory effect (44\%) was found for type D water, and the growth of $69 \%$ of strains was influenced by RDSW with hardness of 1000 over all types A-E.

Little inhibitory effect on bacterial motility was found at a hardness of 100 to 250 . However, the inhibitory effects were found in $56 \%$ of the strains at a hardness of 500 for type E water and in $69 \%$ of the strains at a hardness of 1000 for types A, B and E, in which the calcium contents were high. Overall, irrespective to drug-susceptibility, all 16 strains showed growth and/or motility inhibitions with at least one of types A-E at hardness of 1000 .

\section{Animal experiment}

In H. pylori-inoculated Mongolian gerbils, the decreased CFU in the stomach was observed with all types of RDSW compared with two control waters such as commercial mineral water and RDSW without minerals. The CFU in the stomach showed a particularly significant decrease with RDSW types D and E compared with both control. There was no significant difference between the two control waters.

\begin{tabular}{|c|c|c|c|c|c|c|c|c|}
\hline \multicolumn{3}{|c|}{ Composition of test water } & \multicolumn{2}{|c|}{ Strains with growth inhibition $(n=16)$} & \multicolumn{2}{|c|}{ Strains with motility inhibition $(n=16)$} & \multicolumn{2}{|c|}{$\begin{array}{l}\text { Strains with growth and/or motility } \\
\text { inhibitions }(n=16)\end{array}$} \\
\hline $\begin{array}{l}\text { Type of test } \\
\text { water }\end{array}$ & $\begin{array}{c}\mathrm{Mg} \\
(\mathrm{mg} / \mathrm{L})\end{array}$ & $\begin{array}{c}\mathrm{Ca} \\
(\mathrm{mg} / \mathrm{L})\end{array}$ & Number $(\%)^{*}$ & $\begin{array}{l}\text { Proportion of } \\
\text { strains }\end{array}$ & Number $(\%)^{*}$ & $\begin{array}{c}\text { Proportion of } \\
\text { strains }^{* *}\end{array}$ & Number $(\%)^{*}$ & $\begin{array}{l}\text { Proportion of } \\
\text { strains }\end{array}$ \\
\hline $\begin{array}{l}100-A \\
100-B \\
100-C \\
100-D \\
100-E\end{array}$ & $\begin{array}{c}10 \\
15 \\
20 \\
24 \\
0\end{array}$ & $\begin{array}{c}20 \\
15 \\
7 \\
0 \\
35\end{array}$ & $\begin{array}{l}1 / 16(6 \%) \\
0 / 16(0 \%) \\
0 / 16(0 \%) \\
1 / 16(6 \%) \\
1 / 16(6 \%)\end{array}$ & $13 \%$ & $\begin{array}{l}1 / 16(6 \%) \\
1 / 16(6 \%) \\
2 / 16(13 \%) \\
3 / 16(19 \%) \\
2 / 16(13 \%)\end{array}$ & $31 \%$ & $\begin{array}{l}2 / 16(13 \%) \\
1 / 16(6 \%) \\
2 / 16(13 \%) \\
4 / 16(25 \%) \\
3 / 16(19 \%)\end{array}$ & $44 \%$ \\
\hline $\begin{array}{l}250-A \\
250-B \\
250-C \\
250-D \\
250-E\end{array}$ & $\begin{array}{c}25 \\
38 \\
50 \\
60 \\
0\end{array}$ & $\begin{array}{c}50 \\
38 \\
18 \\
0 \\
88\end{array}$ & $\begin{array}{l}1 / 16(6 \%) \\
2 / 16(13 \%) \\
4 / 16(25 \%) \\
2 / 16(13 \%) \\
3 / 16(19 \%)\end{array}$ & $44 \%$ & $\begin{array}{l}0 / 16(0 \%) \\
1 / 16(6 \%) \\
3 / 16(19 \%) \\
0 / 16(0 \%) \\
2 / 16(13 \%)\end{array}$ & $25 \%$ & $\begin{array}{l}1 / 16(6 \%) \\
2 / 16(13 \%) \\
5 / 16(31 \%) \\
2 / 16(13 \%) \\
5 / 16(31 \%)\end{array}$ & $44 \%$ \\
\hline $\begin{array}{l}500-A \\
500-B \\
500-C \\
500-D \\
500-E\end{array}$ & $\begin{array}{c}50 \\
75 \\
100 \\
120 \\
0\end{array}$ & $\begin{array}{c}100 \\
75 \\
35 \\
0 \\
175\end{array}$ & $\begin{array}{l}1 / 16(6 \%) \\
2 / 16(13 \%) \\
1 / 16(6 \%) \\
2 / 16(13 \%) \\
1 / 16(6 \%)\end{array}$ & $31 \%$ & $\begin{array}{l}0 / 16(0 \%) \\
2 / 16(13 \%) \\
2 / 16(13 \%) \\
2 / 16(13 \%) \\
9 / 16(56 \%)\end{array}$ & $69 \%$ & $\begin{array}{l}1 / 16(6 \%) \\
4 / 16(25 \%) \\
3 / 16(19 \%) \\
4 / 16(25 \%) \\
9 / 16(56 \%)\end{array}$ & $69 \%$ \\
\hline $\begin{array}{l}1000-A \\
1000-B \\
1000-C \\
1000-D \\
1000-E\end{array}$ & $\begin{array}{c}100 \\
150 \\
200 \\
240 \\
0\end{array}$ & $\begin{array}{c}200 \\
150 \\
70 \\
0 \\
350\end{array}$ & $\begin{array}{l}1 / 16(6 \%) \\
4 / 16(25 \%) \\
2 / 16(13 \%) \\
7 / 16(44 \%) \\
2 / 16(13 \%)\end{array}$ & $69 \%$ & $\begin{array}{l}11 / 16(69 \%) \\
11 / 16(69 \%) \\
2 / 16(13 \%) \\
3 / 16(19 \%) \\
11 / 16(69 \%)\end{array}$ & $81 \%$ & $\begin{array}{l}12 / 16(75 \%) \\
12 / 16(75 \%) \\
4 / 16(25 \%) \\
8 / 16(50 \%) \\
11 / 16(69 \%)\end{array}$ & $100 \%$ \\
\hline
\end{tabular}

* Number (\%) of strains affected by each type of RDSW.

** Percentage of strains affected by at least one of types $A$ to $E$. 


\section{Clinical trial}

The percentage of subjects with a successful outcome (reduction rate of $\Delta^{13} \mathrm{C} \geq 7 \%$ ) with control or each test waters in the clinical trial is shown in (Table 3 and Figure 1) A positive effect of the 5 types of RDSW occurred in 40 to $64 \%$ of the subjects, whereas only $28 \%$ of subjects had a successful outcome with control water. In terms of successful outcome, all 5 types of RDSW possessed a higher positive effect to decrease the number of $H$. pylori colonized in the human stomach when compared with control water. Particularly, the effect was significantly observed in types A and C. Furthermore, a significant decrease in the $\Delta^{13} \mathrm{C}$ value was observed after RDSW intake for types $\mathrm{A}$, $\mathrm{B}, \mathrm{C}$ and $\mathrm{D}$ (Figure 2).

\section{Discussion}

\section{In vitro studies}

Overall, the in vitro results demonstrated that the bacterial growth and motility of fewer strains were inhibited when hardness of RDSW was low, and that the number of strains in which these inhibitions occurred increased with an increase in hardness. A change in mineral composition influenced these inhibitory effects at the same water hardness and the effects also differed among the strains.

The proportion of strains showing growth inhibition was higher with RDSW of types C and D at the same hardness. These two types of RDSW contained more magnesium compared with other types, indicating that magnesium has a particular influence on growth inhibition of $H$. pylori. The reduction rate of CFU, an index of growth inhibition, also increased in proportion to increases in hardness and magnesium content. On the other hand, a higher effect of motility inhibition was observed for RDSW of types A, B and E at the same hardness. Since these three types of RDSW contained more calcium than the other types, it appears that calcium has a higher effect of motility inhibition on $\mathrm{H}$. pylori. The reduction rate of migrated colony size on the soft agar medium, an index of motility inhibition, increased in proportion to the increase in hardness and calcium content. Motility of $H$. pylori is sure to be an important factor in persistent infection in the stomach $[18,19]$ and inhibition of bacterial motility results in decreased damage to the host due to low adaptation of microorganism to the environment. In the growth assay, calcium had no influence on the CFUs, however, the colony size was definitely diminished in all the strains, indicating that calcium has somewhat effects on growth inhibition leading to growth delay. Furthermore, we also confirmed that RDSW of hardness 2000, available for drinking water, showed both inhibitory effects in more strains compared to RDSW of hardness 1000 (data not shown). We made the solution adjust by either magnesium from compounds $\left(\mathrm{MgCl}_{2}, \mathrm{Mg}\left(\mathrm{NO}_{3}\right)_{2}, \mathrm{MgSO}_{4}\right.$ and $\left.\left(\mathrm{CH}_{3} \mathrm{COO}\right)_{2} \mathrm{Mg}\right)$ or calcium from compounds $\left(\mathrm{CaCl}_{2}, \mathrm{Ca}\left(\mathrm{NO}_{3}\right)_{2}\right.$ and $\left.\left(\mathrm{CH}_{3} \mathrm{COO}\right)_{2} \mathrm{Ca}\right)$, corresponding to RDSW of hardness 1000 used in this study. The in

\begin{tabular}{|c|c|c|c|c|c|c|}
\hline & \multicolumn{5}{|c|}{ Test water * } & \multirow{2}{*}{$\begin{array}{c}\text { Control } \\
\text { water }\end{array}$} \\
\hline & $A$ & $B$ & C & $\mathrm{D}$ & $E$ & \\
\hline $\begin{array}{l}\text { Number of subjects } \\
\text { with a successful outcome }\end{array}$ & $9 / 16$ & $9 / 19$ & $9 / 14$ & $11 / 20$ & $6 / 15$ & $5 / 18$ \\
\hline $\begin{array}{l}\text { Percentage of subjects } \\
\text { with a successful outcome (\%) }\end{array}$ & $56 \%$ & $47 \%$ & $64 \%$ & $55 \%$ & $40 \%$ & $28 \%$ \\
\hline $\begin{array}{l}\text { Average of decreased value of } \Delta^{13} C \text { in } \\
\text { subjects with a successful outcome }\end{array}$ & 32 & 42 & 39 & 26 & 28 & 18 \\
\hline
\end{tabular}

* RDSW with different Mg:Ca ratios of hardness 1000, as shown in Table 1.

Table 3: Percentage of subjects with a reduction of $\Delta^{13} \mathrm{C} \geq 7 \%$ (defined as a successful outcome) in a clinical trial using 5 types of RDSW.

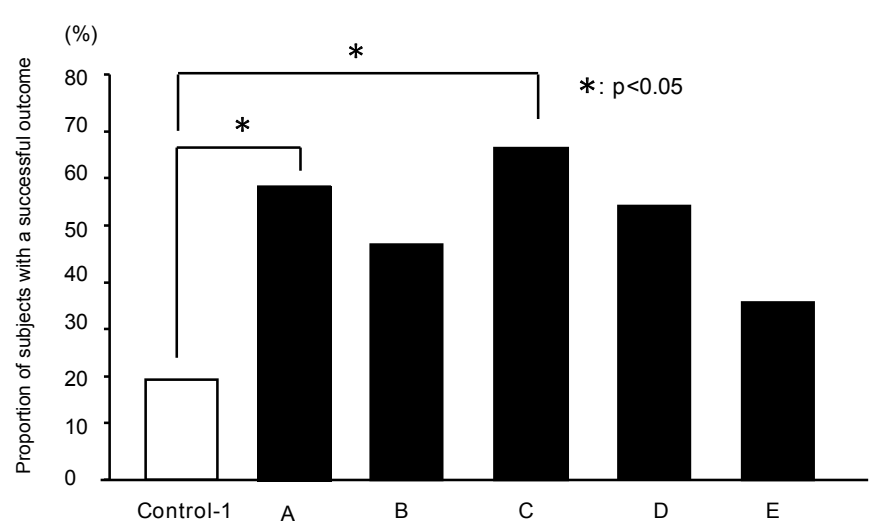

Figure 1: Effects of RDSW on subjects infected with $H$. pylori, showing the proportion of subjects with a successful outcome. Control-1, commercial water; A to E, RDSW with different Mg:Ca ratios of hardness 1000 as shown in Table 1. *Significant difference was observed $(p<0.05)$.

vitro study with these solutions showed the same results from RDSW. The anion of these compounds in the solution possessed no inhibitory effect on $H$. pylori (data not shown). Contrary, RDSW without minerals (RDSW of hardness 0, Control-2 shown in Table 1) demonstrated a loss of such inhibitory effects on $H$. pylori.

These results revealed that magnesium and calcium mainly influence the growth and motility of $H$. pylori, respectively. To elucidate whether the magnesium and calcium are directly exert to microorganism, $H$. pylori was cultured in media containing $1000-\mathrm{D}$ and 1000-E RDSW and the concentrations of magnesium and calcium in isolated bacteria were measured. These concentrations were about 10 times higher than those in controls (data not shown). These results demonstrate that both minerals are adsorbed on the surface or taken into the bacterium, which then suppresses the biological activities of H. pylori. Thus, magnesium and calcium at high concentrations is considered to directly affect the biological behaviors of $H$. pylori such as growth and motility inhibitions, respectively, that occur via different mechanisms in the bacteria. A specific mineral composition is needed to obtain each inhibitory effect efficiently. However, either of the two effects may alleviate the risk of infection, reduce gastric damage and ameliorate symptoms. In this study, meaningful inhibitory effects on H. pylori growth and motility were found in one or more of 5 types of RDSW with a hardness of 1000. Development of new ingredients for treatment and prevention of $H$. pylori infection through anti- $H$. pylori activities requires clarification of the mechanism in which these minerals function with kinetics in the bacteria by a comprehensive genetic analysis. Therefore, microarray analysis with strains exposed to such minerals will be performed to determine how such minerals exert the gene regulation and/or transcriptome of $H$. pylori, which provides us to more understand the mechanisms of such minerals.

\section{Animal experiments}

The animal experiments resulted from $H$. pylori-inoculated Mongolian gerbils demonstrated that all 5 types of RDSW could clearly decrease the CFUs in the stomach compared with two control waters. The CFUs in the stomach decreased with RDSW of types A, $\mathrm{B}$ and $\mathrm{E}$, but with no significant difference when compared with two control waters. However, the in vivo results significantly inhibited the colonization of $H$. pylori by type $\mathrm{C}$ water, in which the $\mathrm{Mg}$ :Ca ratio was 

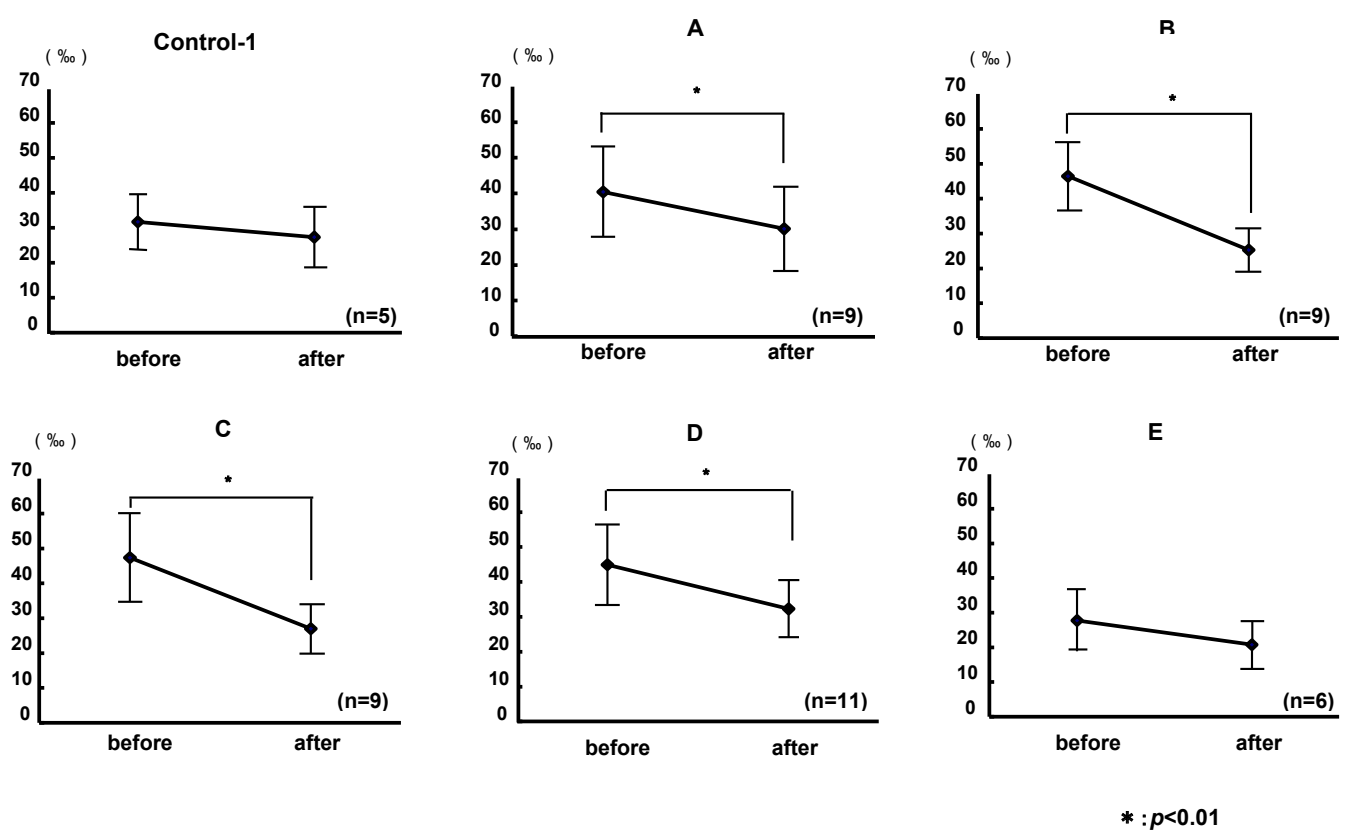

Figure 2: The effects of $\mathrm{Mg}: \mathrm{Ca}$ ratio on changes of $\Delta^{13} \mathrm{C}$ values in subjects with a successful outcome. The $\Delta^{13} \mathrm{C}$ values were compared between "before" and "after" drinking test water. Control-1, commercial water; A to E, RDSW with different Mg:Ca ratios of hardness 1000 as shown in Table 1. Bars show \pm SD (standard deviation). * Significant difference was observed $(p<0.01)$.

3:1, and type D water, which included only magnesium. The greatest inhibitory effects were found with RDSW containing most magnesium, consisted with in vitro results of growth inhibition. Interestingly, type C possessing inhibitory effect on bacterial growth in vitro but not high efficacy showed significantly suppressed the colonization of $H$. pylori in vivo, similar to type $\mathrm{D}$. These results implicate that magnesium is particularly effective for in vivo inhibition of $H$. pylori colonized. The CFUs in the stomach did not differ significantly between two control waters such as commercial mineral water and RDSW without mineral, which suggests that the inhibitory effects on the colonization of $H$. pylori in the stomach of Mongolian gerbils are greatly influenced by calcium and magnesium in RDSW. No difference in the amount of water intake was observed among the control and test waters.

\section{Clinical trials}

Although the animal experiment was limited to only one strain of H. pylori, the results indicated that RDSW had anti-H. pylori activities and lead to decreased number of CFUs in the stomach of Mongolian gerbils. Therefore, the effect of this water on the colonization of $H$. pylori in the human stomach was investigated in volunteers (healthy subjects with $H$. pylori infection). All 5 types of RDSW at a hardness of 1000 definitely showed positive effect in 40 to $64 \%$ of the subjects, compared to only $28 \%$ with control water (commercial mineral water). The positive effect was found for at least one of the 5 types of RDSW in $91 \%$ of the subjects. Among 5 types of RDSW, two RDSWs (types $A$ and C) significantly suppressed the number of CFUs colonized in the stomach compared to control water. In particular, RDSW with the highest proportion of subjects with a positive outcome (64\%) was type $\mathrm{C}$ which was the best effectiveness even in animal experiments. Furthermore, the $\Delta^{13} \mathrm{C}$ value in subjects with a positive outcome significantly decreased after intake of RDSW of types A, B, C and D. Only type E representing $40 \%$ of positive effect, which contains calcium only, failed to produce a significant change in the $\Delta^{13} \mathrm{C}$ value in the human trial.
Taken together, the in vivo strongest effect was found for RDSW of type $\mathrm{C}$ in both the animal and human studies. As described above, H. pylori adsorbs and/or absorbs calcium and magnesium, and a good balance of minerals may increase the efficacy of adsorption and absorption. A Mg:Ca ratio of 3:1 may promote intake into the bacterium and produce a better inhibitory effect than single use of each mineral. Alternatively, direct growth inhibition in vivo by magnesium and motility inhibition by calcium may produce synergistic inhibitory effects leading to decreased number of $H$. pylori colonized in the stomach.

Generally regarding human pathogenesis with microorganisms including $H$. pylori, the bacterial number colonized in the tissue is clearly an important factor and is associated with manifestations of infectious disease including symptoms and development of pathogenesis [20,21]. It was reported that the number of $H$. pylori in the gastric mucosal tissue was significantly larger in the group with duodenal ulcer than that without duodenal ulcer [17]. These findings indicated that reduction of the number of $H$. pylori colonized in the stomach and improvement of the microenvironment of the gastric mucosa may reduce the risk for development of gastro-duodenal diseases, even in asymptomatic people infected with $H$. pylori. Furthermore, in case of $H$. pylori-associated ITP, decreased number of $H$. pylori leads to increased number of platelet even in unsuccessful case of eradication therapy [5].

Other than the anti-H. pylori activities found in this study, RDSW has been shown to improve atopic dermatitis in humans [10], delay cataract occurrence in the hereditary cataract SCR rat [15], prevent arteriosclerosis in rabbit, [12] and improve cardiovascular dynamics in a hereditary hypercholesterolemia (KHC) rabbit model [11]. Thus, drinking RDSW contributes to maintain human health with improvement of mineral deficits. Intakes of RDSW cause neither a side effect nor influence the medicine $[16,17]$ and continuous intake as drinking water is possible. Since the effective mineral ratio varies 
Citation: Kawada M, Takeuchi H, Con SA, Yamamoto E, Yasukawa T, et al. (2012) Antibacterial Activities of Refined Deep Seawater on Helicobacter pylori. J Medical Microbiol Diagnosis S1:002. doi:10.4172/2161-0703.S1-002

according to individual strains of $H$. pylori, an analysis of the functional mechanism of calcium and magnesium in ant $-H$. pylori activities may enable development of a RDSW product that corresponds to each $H$. pylori strain (or person infected with $H$. pylori). This is the first report to show that RDSW is effective against infectious diseases caused by H. pylori. The results raised the possibility that RDSW can be used for adjunct treatment or prevention of $H$. pylori infection and promotion of general human health. The clinical trial with 170 patients by the Osaka Association of General Physicians demonstrated that RDSW (type-C) effectively relieved outpatients of their constipation and abdominal discomfort, was safe combined with pharmaceutical agents, and is useful in clinical practice [17]. However, we may pay attention regarding combined effect with medicines such as thiazide diuretic and antibiotics including tetracycline and quinolone. Thus we need to extend the clinical studies in term of combined effect between RDSW and antibiotics to confirm the clinical application such as effectiveness and safety in patients. The accumulated findings of RDSW should provide a promising way which even patient can use daily in their life.

\section{Acknowledgments}

This study was partially supported by The Kochi University President's Discretionary Grant (to Takeuchi).

\section{References}

1. Goodwin CS (1997) Helicobacter pylori gastritis, peptic ulcer, and gastric cancer: clinical and molecular aspects. Clin Infect Dis 25: 1017-1019.

2. Cotton P (1994) NIH Consensus Conferences. Helicobacter pylori in peptic ulcer disease. NIH consensus Development panel on Helicobacter pylori in peptic ulcer disease. JAMA 272: 65-69.

3. Parsonnet J, Friedman GD, Vandersteen DP, Chang Y, Vogelman JH, et al.( 1991) Helicobacter pylori infection and the risk of gastric carcinoma. $N$ Engl J Med 325: 1127-1131.

4. Hatakeyama M (2008) Oncogenic mechanism of Helicobacter pylori. Nihon Rinsho Meneki Gakkai Kaishi 31: 132-140.

5. Morimoto N, Takeuchi H, Takahashi T, Ueta T, Tanizawa Y, et al. (2007) Helicobacter pylori-associated chronic idiopathic thrombocytopenic purpura and low molecular weight $H$. pylori proteins. Scand J Infect Dis 39: 409-416.

6. Mabe K, Yamada M, Oguni I, Takahashi T (1999) In vitro and in vivo activities of tea catechins against Helicobacter pylori. Antimicrob Agents Chemother 43 1788-1791.

7. al Somal N, Coley KE, Molan PC, Hancock BM (1994) Susceptibility of Helicobacter pylori to the antibacterial activity of manuka honey. J R Soc Med 87: 9-12.

8. Sgouras D, Maragkoudakis P, Petraki K, Martinez-Gonzalez B, Eriotou E, et al (2004) In vitro and in vivo inhibition of Helicobacter pylori by Lactobacillus casei strain Shirota. Appl Environ Microbiol 70: 518-526.

9. Zhang L, Ma J, Pan K, Go VL, Chen J, et al. (2005) Efficacy of cranberry juice on Helicobacter pylori infection: a double-blind, randomized placebo-controlled trial. Helicobacter 10: 139-145.

10. Hataguchi $\mathrm{Y}$, Tai H, Nakajima H, Kimata H (2005) Drinking deep-sea water restores mineral imbalance in atopic eczema/dermatitis syndrome. Eur J Clin Nutr 59: 1093-1096.

11. Katsuda S, Yasukawa T, Nakagawa K, Miyake M, Yamasaki M, et al. (2008) Deep-sea water improves cardiovascular hemodynamics in Kurosawa and Kusanagi-Hypercholesterolemic (KHC) rabbits. Biol Pharm Bull 31: 38-44.

12. Miyamura M, Yoshioka S, Hamada A, Takuma D, Yokota J, et al. (2004)

This article was originally published in a special issue, Bacterial Pathogenecity \& Epidemiology handled by Editor(s). Dr. Morabito Stefano, National Institute of Health, Italy
Difference between deep seawater and surface seawater in the preventive effect of atherosclerosis. Biol Pharm Bull 27: 1784-1787.

13. Takeuchi $H$, Nakazawa T, Okamoto T, Shirai M, Kimoto M, et al. (2006) Cell elongation and cell death of Helicobacter pylori is modulated by the disruption of cdrA (cell division-related gene A). Microbiol Immunol 50: 487-497.

14. Shibayama K, Takeuchi H, Wachino J, Mori S, Arakawa Y (2011) Biochemical and pathophysiological characterization of Helicobacter pylori asparaginase. Microbiol Immunol 55: 408-417.

15. Nagai N, Ito Y, Inomata M, Shumiya S, Tai H, et al. (2006) Delay of cataract development in the shumiya cataract rat by the administration of drinkingwater containing high concentration of magnesium ion. Biol Pharm Bull 29: 12341238.

16. Tsuchiya Y, Watanabe A, Fujisawa N, Kaneko T, Ishizu T, et al. (2004) Effects of desalted deep seawater on hematologic and blood chemical values in mice. Tohoku J Exp Med 203: 175-182.

17. Izuoka T, Toyama M, Higuchi T, Kobayashi K, Mitsui H, et al. (2009) Postmarketing functional food survey: efficacy and safety of magnesiumcontaining mineral water for patients with constipation. Journal of Japan Physicians Association (JJPA) 24: 102-107

18. Eaton KA, Morgan DR, Krakowka S (1992) Motility as a factor in the colonization of gnotobiotic piglets by Helicobacter pylori. J Med Microbiol 37: 123-127.

19. Eaton KA, Suerbaum S, Josenhans C, Krakowka S (1996) Colonization of gnotobiotic piglets by Helicobacter pylori deficient in two flagellin genes. Infect Immun 64: 2445-2448.

20. Khulusi S, Mendall MA, Patel P, Levy J, Badve S, et al. (1995) Helicobacter pylori infection density and gastric inflammation in duodenal ulcer and nonulcer subjects. Gut 37: 319-324.

21. Correa P (1984) Chronic gastritis as a cancer precursor. Scand J Gastroenterol Suppl 104: 131-136.

\section{Submit your next manuscript and get advantages of OMICS Group submissions}

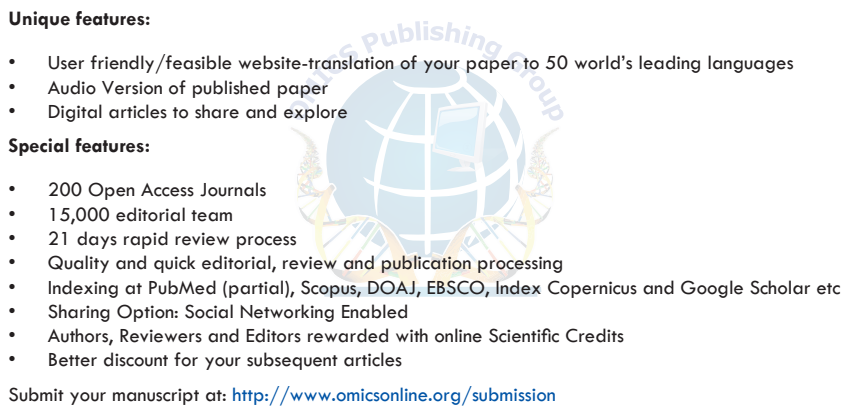


